This is a self-archived version of an original article. This version may differ from the original in pagination and typographic details. Author(s): Sampson, James P.; Osborn, Debra S.; Kettunen, Jaana; Hou, Pei-Chun; Miller,
Adam K.; Makela, Julia P.

Title: The Validity of Social Media-Based Career Information

Year: 2018

Version: Accepted version (Final draft)

Copyright: (c) 2018 by the National Career Development Association.

Rights: In Copyright

Rights url: http://rightsstatements.org/page/lnC/1.0/?language=en

Please cite the original version:

Sampson, J. P., Osborn, D. S., Kettunen, J., Hou, P., Miller, A. K., \& Makela, J. P. (2018). The Validity of Social Media-Based Career Information. Career Development Quarterly, 66(2), 121134. https://doi.org/10.1002/cdq.12127 


\title{
The Validity of Social Media-Based Career Information
}

\author{
James P. Sampson, Jr. \\ Department of Educational Psychology and Learning Systems \\ Florida State University \\ Debra S. Osborn \\ Department of Educational Psychology and Learning Systems \\ Florida State University \\ Jaana Kettunen \\ Finnish Institute for Educational Research \\ University of Jyväskylä \\ Pei-Chun Hou \\ Department of Educational Psychology and Learning Systems \\ Florida State University \\ Adam K. Miller \\ Department of Educational Psychology and Learning Systems \\ Florida State University \\ Julia P. Makela \\ The Career Center \\ University of Illinois
}

Author note: Robert Reardon, Matthew Sampson, and Sandy Sampson provided helpful reviews of the manuscript.

\section{Corresponding Author:}

James P. Sampson, Jr.

The Career Center

Florida State University

100 South Woodward Avenue

Tallahassee, Florida 32306-4162

(850) 322-8918

Email: jsampson@fsu.edu 
The Validity of Social Media-Based Career Information 


\begin{abstract}
The use of social media expands the availability and sources of career information. However, the authorship of this information has changed from traditional print media and multimedia sources created by experts to social media-based career information created by the users themselves. While variability in career information validity has been an issue for some time, rapid growth in the use of social media creates some unique challenges. The ease with which social media-based career information can spread creates the potential for rapid widespread dissemination of disinformation and biased perceptions. Potential sources of invalidity include: intentional bias (with or without profit motive), unintentional bias, restricted range of experience, out-of-date information, popularity bias, similarity bias, and context deficiency. We examine potential sources of social media-based career information invalidity and suggest implications for practice to help individuals make best use of such information.
\end{abstract}

Key Words: career information, social media, information validity, bias, misinformation 


\section{The Validity of Social Media-Based Career Information}

Making informed occupational, educational, training, or employment decisions depends on having adequate knowledge of available options (Sampson, Reardon, Peterson, \& Lenz, 2004). However, results from a 2011 Harris Interactive Study (National Career Development Association [NCDA], 2011) indicated that only $16 \%$ of participants reported using career information for their career planning, and that 59\% would want more or different information about their options if making another career decision.

Options knowledge includes important characteristics of occupations, programs of study, or jobs. Options knowledge helps (a) motivate individuals to exert the effort needed to make a decision; (b) clarify what is important in terms of individuals' values, interests, skills, and employment preferences; (c) generate and evaluate options; and (d) implement a decision. Individuals gain options knowledge as a result of their own life experience, by observing others' experience in real life or through the media, and through reading or viewing career information (Sampson et al., 2004). “Career information comprises educational, occupational, industry, financial aid, job search, and related information for career development" (Alliance of Career Resource Professionals, 2016b, p. 1).

The delivery of career information is a common element in the provision of self-help to individuals and practitioner-assisted career services to clients (Sampson et al., 2004). The dissemination of career information was found to be the most common use of information and communication technology (ICT) in the provision of career services (Bimrose, Hughes, \& Barnes, 2011). The dissemination of information both via the Internet and mobile applications has dramatically increased in recent years (Sampson \& Osborn, 2014), and many people indicate using the Internet when searching for career-related information (NCDA, 2011). In a meta- 
analysis of career intervention studies, Brown and Ryan Krane (2000) found the provision of world-of-work information to be one of five key ingredients of effective career interventions. In addition, NCDA (ncda.org) identifies the delivery of information/resources as well as technology as competency areas for career practitioners, and outlines standards related to the provision of career information and technology. Thus, career practitioners must be knowledgeable and skilled in the various formats and venues through which career information exists.

Career information is provided in a variety of formats including text, images, audio, and multimedia. Over time, the delivery of career information has shifted from print media and analog multimedia to digital content on personal computers, the Internet, and mobile devices. The Internet has also evolved considerably over time (e.g., Hooley, Hutchinson, \& Watts, 2010). Early applications focused on information delivery from author to audience. The notion of a second generation of the Internet characterized by substantially increased sharing of information among users is reflected in the concept of Web 2.0 (e.g., Hooley, Shepherd, \& Dodd, 2015; O'Reilly, 2007). This second generation of the Internet, which refers to technology characterized as being user-centered, open, participatory, interactive and knowledge sharing, poses a blend of new opportunities and challenges in the creation and delivery of career information. With the next generation technologies already on the horizon, key opportunities include increased access to hard-to-reach client populations in familiar spaces, at flexible times, in creative ways. A key challenge is the potential delivery of invalid career information that has been created by individuals and widely distributed. In addition, career practitioners may have to address misperceptions based on clients' acceptance of social media-based career information. Against this backdrop, we examine potential sources of social media-based career information invalidity and implications for career practice in helping individuals make best use 
of social media-based career information. First, we set the context with a discussion of career information validity. This is followed by an examination of social media-based career information, including social media and social media tools, as well as accessing social mediabased career information with examples provided of how different clients might use various tools in career and occupational exploration. Finally, several potential sources of invalidity are identified, and implications for career practitioners and researchers are provided.

\section{The Validity of Career Information}

Making an informed career decision is dependent on the validity of the career information available, and career practitioners have a responsibility to "assist clients in determining the validity and reliability of information found on websites and in other technology applications" (NCDA Code of Ethics, 2015, p. 17). The eventual appropriateness of a career choice can be compromised if the information used by individuals is invalid. Several recurring characteristics have been identified (e.g., Bimrose \& Barnes, 2011; NCDA, 1991, 1992a, 1992b) as indicators of the validity of career information, including accuracy, understandable, lacking bias, reflecting currency (timewise) and comprehensiveness. Other characteristics require that information be "developmentally appropriate, relevant, specific," (Alliance of Career Resource Professionals, 2016b, p. 1). Evaluation criteria for social media-based information include accuracy, authority, comprehensiveness, logic, and verifiability (Kim, Sin, \& Yoo-Lee, 2014).

With the preceding literature in mind, the following definition and elements of career information validity are proposed. Career information validity concerns the accumulated evidence that an information source is comprehensive, accurate, and relevant for the decision being made, as well as being understandable to the decision maker. Comprehensiveness of career information concerns the accumulated evidence that the data presented includes all of the 
relevant topics necessary for making an informed decision by persons at various developmental stages. Accuracy of career information concerns the accumulated evidence that the data presented are current, credible, verifiable, and impartial. The source gathering and presenting the information should be made clear so that the reader can be made aware of any potential bias. Relevancy for the decision being made is the accumulated evidence that the data presented contributes to a specific type of decision an individual needs to make, such as using employment projection data in making education and training decisions. Understandable to the decision maker is the accumulated evidence that the data are presented in a way that is appropriate for the developmental characteristics of the learner.

Variability in career information validity has been an issue for some time (Offer \& Sampson, 1999) and remains an issue today (Makela \& Kettunen, submitted; Sampson \& Makela, 2014). Hooley et al. (2015, p. 50) noted that "well validated, usable, consistently updated websites based on good research sit side by side with incoherent nonsense." With the explosion of social media, numerous career-related tools are traded virally between users without evidence of validity. A well-designed website with attractive graphics is no guarantee of quality (Sampson \& Lumsden, 2000). Hooley et al. (2015) further stated that the quality of information available can be influenced by the nature of the provider. Information from public sector sources tends to be impartial, while private sector sites vary considerably in quality (Hooley et al., 2015).

\section{Social Media-Based Career Information}

Social media-based career information is defined as perceptual data on occupations, education, training, and employment created by an individual or groups of individuals using various social media tools and social networking technologies with different types and amounts of life experience influencing their perceptions over time. The examination of social media- 
based career information begins with a description of social media and social media tools and continues with options for accessing social media-based career information, examples of social media-based career information, and potential sources of information invalidity.

\section{Social Media and Social Media Tools}

Social media is defined as a process whereby individuals and groups build a common understanding and meaning with contents, communities, and Web 2.0 technology (Ahlqvist, Bäck, Heinonen, \& Halonen, 2010; Kolbitsch \& Maurer, 2006). As such, social media refers primarily to types of practices, as opposed to a specific set of technologies (Dohn, 2009). Note that, in this paper, we distinguish social networking technologies (SNTs) as a subset of social media. Social networking is a form of social media that emphasizes relationship and community building. SNTs provide an online space for connections to be built among people who share common interests (Makela, 2015). Examples of social media tools include "Wikipedia, blogs, user reviews, social networking sites (SNS), video sharing sites, microblogs, and social Q\&A sites" (Kim et al., 2014, p. 446). Discussion threads, or comments from responders to specific topics provide the opportunity to explore aspects of career interventions. For example, individuals could provide tips on how to prepare for a career fair or employment interview. Bimrose, Kettunen, and Goddard (2015) noted that discussion threads allow practitioners and individuals to apply career information to decision making.

The availability of social media has resulted in more diverse authors of career information (Hooley et al., 2010, p. 6). Individuals now have the capability to develop and disseminate information to others (Bimrose \& Barnes, 2011; Hooley, 2012; Kettunen, Vuorinen, \& Sampson, 2015b; Makela, 2015; Sampson \& Osborn, 2014). By publicly sharing their 
reflections on what they are learning, individuals using social media become producers of information (Kettunen, Sampson, \& Vuorinen, 2015a).

\section{Accessing Social Media-Based Career Information}

Individuals access social media-based career information either intentionally or unintentionally. In the intentional mode, individuals gain career information by using search features to find information in social media or post a question that leads to an answer or further discussion. Even if individuals have no specific question in mind, they can gain career information by intentionally joining online communities where resources about occupations, education, training and employment are shared, research is advertised, and ideas and comments are exchanged. Proactivity plays an important role in obtaining career information in this mode.

In the unintentional mode, individuals gain career information as they browse posts, tweets, discussion threads, social networking sites, images or videos for some other purpose. Serendipity and reactivity play an important role in obtaining career information. In both modes, using social media may lead individuals to follow an embedded link, or post or tweet a comment or a question, in order to gain further information. The increased opportunity for serendipity and reactivity differentiates the use of social media to obtain career information from more traditional print and video-based forms of career information.

\section{Examples of Social Media-Based Career Information}

When a person making an occupational, educational, training, or employment choice uses Web search features to find more specific information on different industries and occupations, it is likely that the resources identified contain social media-based information. Industry and occupation wikis with content created or edited by multiple users contain many entries about particular fields and occupations that persons may consider as authoritative information sources. 
A number of different types of blogs, usually written in chronological order by an individual or groups of individuals, provide more personal entries and opinion pieces. Blogs often offer the reader an opportunity to comment about a particular blog post or ask questions, and some bloggers engage in discussion with their readers. Wikis and blogs generally offer readers compilations of links to other wiki and blog entries recommended or commented by the author(s) and further information sources such as content communities and social networking sites. These sites related to different occupations, educational options, or employers enable people with similar interests to connect. More specifically, individuals who share a common interest can collaboratively discuss and share information and resources on different occupations, educational options, or employers. At its best, career practitioners actively participate and engage in social media interactions in which meanings and understandings are co-constructed. Three specific examples follow that show the use of social media-based career information for occupational, educational, and employment decisions. These examples are limited to social media-based information. Other sources of career information could and should also be used.

Example of a college sophomore making an occupational decision. A 19-year-old college sophomore is in the process of making an occupational decision that will impact her selection of courses in her accounting major. She is choosing between a track in public accounting and a track in auditing that would lead to different employment options. She chats (synchronously) with some of her friends to discuss her plans and they urged her to reach out to others who had graduated and were seeking employment. She uses Facebook to solicit feedback from wider circle of friends and fellow students as to which option seemed to offer opportunities for travel and rapid advancement. She intentionally searched the Internet for more information about accounting and auditing, employment options, job profiles and expected salaries. Based on 
her search results she accessed several blogs (and associated Reddit "Ask Me Anything" discussion threads) on opportunities in accounting and auditing. One of the blog posts was written by a career counselor discussing strategies in making occupational decisions in business. She posted a question to a blog post of an accounting student who achieved a master's degree and had become employed, which led to an interesting discussion with the blog-author and other blog-readers. Through this interaction she obtained diverse opinions and the posts led her to audio podcasts and videos that provided interviews of currently employed public accountants and auditors describing their work. She followed a link posted on a Facebook group by a college senior and connected with fellow students from around the world by joining an international group in LinkedIn. She found that there are useful accounting apps for students and professionals and decided to download them to keep up-to-date with the latest insights in the field. She used Twitter to post her reactions to what she was learning, to process her experience, and to get feedback from her followers. Some of her tweets were shared and replied to and she got into a tweet discussion with a professional in auditing. In addition, she spent some time in Second Life searching for, joining, and talking with various groups with interests in accounting, such as CPA Island, which hosts various speakers' series and broadcasts.

Example of a high school student making an educational decision. An 18-year-old high school senior is in the process of making an educational decision between living at home and attending the local community college and living in a residence hall at a state college three hours away from home. He exchanges opinions of both options with his friends on a chat, on instant message, and over the phone. He posts a question on Facebook inviting his friends, peers and family who have attended both colleges to share their experience, specifically asking, "If you had to do it all over again, would you choose the same college and why?" He intentionally 
searched the Internet for more information about pros and cons of living at home during college as well as living in a residence hall at a state college. Based on his search results he accessed a couple of blogs and posted a question on a discussion thread of a former college student who shared her experiences to help soon-to-be college students that are trying to figure out if living at home might be the right decision for them. Through this interaction he obtained the opinions of others with emphasis on choosing a college that best meets your needs and finances. He also followed Twitter feeds associated with each college to receive information streamed to him without having to retrieve information himself. He posted a tweet about finding the best college fit. Someone on Twitter saw his tweet and reached out to State college, informing them about the message. An alumnus of the State college responded to his tweet and offered to provide additional information via one-to-one chat. After the chat he accessed the web site for each college and followed links to additional information that existed on college social media. Sites provided him with photos and videos of students describing their experiences at each college, where he paid particular attention to the differences between maintaining existing friendships in his hometown and making new friends in another city. In Second Life, he searched the Education Directory (http://wiki.secondlife.com/wiki/Second_Life_Education_Directory) and found one of his choices represented there. He visited that inworld campus and was able to find some avatars to talk with. He also did a search on Second Life to locate alumni of both of his options, subsequently finding alumni groups and initiating conversations with the members.

Example of an adult making an employment decision. A 35-year-old chemical engineer is in the process of making an employment decision after being encouraged by her employer to change positions from the research and development department to a position in the company as a line manager in agribusiness. She is also considering relocating to her hometown 
in another state where an executive search consultant has identified a management position in agribusiness. She used social networking, especially Facebook, to get feedback from friends about the advantages and disadvantages of both relocating and switching employers. Her friends urged her to seek input from a career development practitioner on what to consider before changing jobs. A career counselor provided counseling at a distance to help her identify appropriate sources of information and to periodically help her process what she had learned. In LinkedIn she searched, drilled down, and joined groups relevant to her skills to keep up with what is going on. She discovered that an old college friend who works at the same company where she is considering to relocate. She sends him an InMail message asking if he has time available to give her some insights into the company. She searched for blogs using Google that mentioned career change in chemical engineering, as well as Reddit to search for career transition communities. She also searched for video sharing sites and Wiki sites related to chemical engineering to better understand her options. She then used Twitter to get feedback on the accuracy of her perceptions about changing employers in chemical engineering.

The cases presented included high school, college, and adult examples making educational, occupational, and employment decisions using a variety of social media tools to gain information and opinions about the options they were considering. The challenge for each of these cases is sifting through what information is valid and what might be invalid.

\section{Potential Sources of Invalidity in Social Media-Based Career Information}

Due to the relatively recent nature of social media-based career information, little is known about the validity of this information. However, concerns about validity have been raised. Kim et al. (2014) cautioned that the quality of socially constructed information is bound to vary greatly as it is written by potentially biased individuals with differing degrees of information 
validation. Furthermore, while it is true that access to information on the Internet is improved when there is no cost to the user, this improved access can create a validity problem. For example, Hooley et al. (2010) noted that when information is being published for free or a very low price, the expectation for information to be vetted as accurate might be lower or nonexistent. Adding to the challenge, Makela (2015) noted that it is difficult to assess the accuracy of online information because the materials posted often lack indications of authors' identities, dates materials were created, geographic locations, and other contextual information. Information invalidity can result from several potential causes, including (a) intentional bias (with or without profit motive), (b) unintentional bias, (c) restricted range of experience, (d) outof-date information, (e) popularity bias, (f) similarity bias, and (g) context deficiency.

Intentional bias. Intentional bias involves a conscious attempt to influence the decisions and behavior of others by presenting inaccurate or partial information. Two subtypes exist based on the motivation of the author of the information. In the first subtype the author is trying to influence others based on gratitude or revenge without any goal of making a profit. For example, an individual may believe: "I love teaching and want to attract others to the field, so I will only post positives about my job." Or, "I was treated unfairly at my job so I will post negative, or exaggerated opinions." In the second subtype of intentional bias, the author represents a business and presents selected information that is most likely to motivate an individual to make a purchase, such as posts that are meant to lure a reader into following the writer's site, attending a training provided by the writer, or purchasing related materials.

In the high school student example from the previous section, a potential opportunity for intentional bias occurs when the student connects with an alumnus of the State college via oneon-one online chat. This engagement is likely conducted in a recruiting context, meaning that the 
alumnus who is very proud of the institution may be less likely to present negative or disconfirming information about State college, preferring instead to present information only in a favorable light. The high school student will want to keep the potential biased nature of this source in mind when considering information obtained, and may want to engage in follow-up conversations with a more neutral source.

Unintentional bias. Unintentional bias involves an unconscious attempt to influence the decisions and behavior of others by presenting inaccurate or partial information. For example, an individual may be unaware of prejudicial and stereotypical beliefs, that are regularly reinforced by his or her family or cultural group, and these beliefs inappropriately influence content he or she posts in discussion threads, social networking sites, blogs, and video posts. Unintentional bias results from a person's assumptions and worldview regarding career.

The college student in the examples provided sought out "diverse opinions" through the use of audio posts and videos of those employed in career fields that fit her interests. She would do well to be aware of unintentional bias in these resources, recognizing that those committed to the field may limit their discussions to their positive and affirming experiences.

Restricted range of experience. Restricted range of experience is similar in nature to unintentional bias in that it is unintended. However, the specific source of potential harm results from the overgeneralization of one individual's experience with an occupation, education, training, or employment in a way that does not reflect the norm. For example, an individual may reflect, "I was a social worker and all I did was sit in my cubicle and fill out paperwork. I never interacted with any clients. This is not really a job for those interested in people."

Restricted range of experience may be present in the case of the college student who is making an occupational choice in the examples above. One of the blog posts she read 
emphasized that auditing positions have no opportunities for advancement while accounting positions have ample opportunities for promotion. The individual writing this blog (an accountant) has only worked for one company that has outsourced many auditing functions leading to reduced opportunities for advancement in that one company that is not reflective of the industry in general.

Out-of-date information. Out-of-date information involves individuals presenting information from their experience that was valid in the past, but does not reflect the current reality in occupations, education, training, or employment. For example, an individual may reflect, "When I worked in sales the best tool I had was the telephone directory to identify potential clients for cold calling." As a result of the low cost of publishing information on the Internet, there is no financial incentive to remove out-of-date information (Sampson \& Makela, 2014). Internet-based information has tendency to be enduring and public (Makela, 2015).

The adult making a career change in the examples above may also encounter this challenge as she relies on Google to search for blogs with career changing advice. Information obtained may be dated, or it may be difficult to discern the source and timeliness of a reference.

Popularity bias. Popularity bias involves the perception that something is true simply because many people state it to be true even when objective data may suggest otherwise. For example, an observation in text or video that supports an existing perception may be more likely to be reposted and subsequently more likely to be identified by search engines. This can create a multiplier effect where inaccurate and biased information becomes "more true" as the information is forwarded to others. Kim et al. (2014) noted that unsuspecting viewers may misjudge the credibility of information as being credible when it is found on many sites and reposted by many users. 
The college student in the examples appears to be using popularity as a factor in several of her inquiries. For example, she assesses feedback on which field (public accounting vs. auditing) offers greater advancement and travel opportunities through a Facebook poll of students and friends. It may be interesting for her to ask not only what students believe, but on what they are basing this information.

Similarity bias. Similarity bias involves the perception that something is true because the person or persons creating the social media are similar to the person reading or viewing the career information, even if the information is in fact false. Shen (2016) found that social media content with more apparent similarity between the characteristics of the creator and the reader/viewer were evaluated as more trustworthy. Characteristics of similarity included demographics, attitudes and background. For example, an individual may read a blog post and subsequent discussion thread from a person who looks similar and has a similar career problem, and subsequently make a decision based on information that may have been inaccurate and biased.

In the high school student example, the student focuses many of his inquiries and searches on exploring the experiences of friends, peers, family, and students who have attended college, asking them to share their experiences. He may be tempted to assume that since he has many similarities with these individuals that their perspective must be true. It may be helpful for him to have a strategy for recognizing bias, as well as balancing the information that is coming from these sources with other sources of information.

Context deficiency. Context deficiency involves a lack of supplemental data necessary to evaluate and use career information typically caused by size restrictions in data files transmitted by social media tools. Kim et al. (2014) noted that these limits can force a reduction in 
contextual information, also called information fragmentation, which in turn, makes it difficult to completely understand and evaluate information quality. Valuable contextual data for information that may be missing include creation date and geographic location, as well as cultural, visual, and affective cues. Such contextual gaps may create misunderstandings that are difficult to correct (Makela, 2015). For example, a short blog post may not provide enough detail on the creator's educational and employment history to show the context for the conclusions reached about the lack of advancement opportunity in a particular occupation.

While every person's career decision making experience is unique, consider the complexity of the adult career changer example provided above. She is considering multiple years of work experience, opportunities for advancement, anxiety about learning new competency areas, and a potential geographic move to her hometown. The chances of connecting with an individual or resources online that are a strong match for all the dynamics of her career decision are fairly low. It is helpful to think of online resources as one type of resource in her overall toolbox. She may benefit from other supports that can help tailor resources such as these to her unique situation.

\section{Implications for Practice}

While little empirical evidence exists regarding the extent and impact of social mediabased career information, some evidence exists that use of social media for career development purposes is widespread. For example, according to a national survey conducted by the National Association of Colleges and Employers (NACE, 2013), 95\% of graduating college seniors who planned to enter the job market reported having online social media profiles. The most commonly used sites included Facebook (90\%), LinkedIn (62\%), and Twitter (44\%). Further, $53 \%$ of graduating college seniors indicated that they actively used social media as a part of their 
job search. Recognizing that social media-based career information poses some unique validity challenges, the current wide availability of social media-based career information requires a thoughtful response from career practitioners. Three initiatives seem appropriate at this point: (a) practitioners contributing to the information and digital literacy of individuals and clients, (b) practitioners developing their skills in creating social media and in using social media tools, and (c) practitioners expanding their professional role to include active participation in social media as part of service delivery. Each of these will be briefly explored in the next paragraphs.

Appropriately selecting and using social media-based career information is dependent on individuals and clients having skills in information literacy and digital literacy. Practitioners have an important role in supporting the development of the literacy of their clients (Hooley et al., 2010). Information literacy involves recognizing that information is needed, followed by the capacity to locate, critically evaluate, and effectively use the information (Association of College and Research Libraries, 2000). Digital literacy in career development involves the capacity to critically: (a) understand the nature of career information online, (b) analyze the origins of the career information, and (c) consider the usefulness of the career information (Hooley, 2012). Individuals' ability to assess the veracity and value of the information available to them is an important element of effective use (Howieson \& Semple, 2013), as is, understanding author bias, and the degree to which their viewpoint is affecting the information (Hooley et al., 2010). Career practitioners have a responsibility to teach individuals and clients to be critical consumers of all information (Offer \& Sampson, 1999; Zalaquett \& Osborn, 2007) including potential sources of career information invalidity, such as the seven types outlined in this paper.

One method for doing this would be to utilize existing tools such as those provided by NCDA (1991, 1992a, 1992b) for evaluating information sources. Also, a career practitioner 
might model with a client how to identify, evaluate, and use career information from various sources. A brief guide on evaluating career information that includes some of the sources of invalidity outlined in this paper (e.g., out-of-date information or restricted range of experience) could be provided to clients. When there are discrepancies in the information, clients should be encouraged to seek the reasons for those discrepancies. In addition, career practitioners have an ethical responsibility to educate clients on the potential risks and benefits of using social media tools in career exploration and career decision making (NCDA, 2015, Section F.7.h). Finally, career practitioners might encourage clients to cast a wide net in searching for career information and then weigh all the information together. In some cases, social media-based career information may be more valid and relevant than general information that is posted in employer or professional association sites. For example, an employer website is likely to only include positive information, whereas social media can highlight negative experiences of previous employees. These efforts should begin in career interventions in schools and continue as part of lifelong learning (Hooley et al., 2010). The importance of this recommendation is underscored by Howieson and Semple (2013), who identified that few young people were worried about the quality of the information they were reading.

In order to help individuals and clients select and make effective use of valid social media-based career information, practitioners need to be actively engaged themselves in the use of social media tools. Preservice and in-service training on this topic is essential (Bimrose et al., 2011; Hooley et al., 2015; Kettunen et al., 2015a). Training is necessary to develop practitioner skills and knowledge in this area including an awareness of the function of social media, how to assist individuals in using social media in making career decisions, and the ethical issues in social media use (Kettunen et al, 2015a; Makela, 2015). 
Finally, practitioners need to expand their professional role to include active participation in social media as part of service delivery (Kettunen et al., 2015a). Practitioners who have clients using social media need to establish a presence in social media. Participating in a discussion thread associated with a blog post may have a broad impact on clients. This type of intervention with many individuals may be as valuable as counseling with a limited number of clients. This “one to many" type of interaction (Hooley, 2012) provides an opportunity for practitioners to leverage their expertise to reach a larger percentage of citizens than ever before. Practitioners who participate in social media need to provide valid information, address misinformation that may arise in comments or discussions, and refer individuals to sources of valid career information and practitioner-supported career services when more assistance is needed.

\section{Implications for Research}

Empirical studies on social media-based career information is limited, and thus a recommended research strategy would be to begin with descriptive research, followed by documenting best practices and establishing evidence-based practice. In terms of descriptive research, the following questions provide a starting point for investigation. What type of social media-based career information is available? What is the source (or authorship) of the information, and what biases might that source hold? What tools are used to deliver the information? Who is using the information? How are individuals using social media to inform their career decisions? What are the criteria that individuals use when determining which information sources are valid and which are not? In terms of best practices, which strategies explicitly address the development of information literacy in individuals using self-help resources and in clients using career services? When and how do practitioners engage with individuals and clients to make effective use of social media-based career information? What 
professional standards show the most promise in helping practitioners implement social mediabased career information into their work? In terms of evidence-based practice, which types of social media-based career information contribute best to informed career exploration and decision making? What is the differential impact of self-help and practitioner-supported interventions using social media-based career information? How do individual and client characteristics influence the effectiveness of self-help and practitioner-supported interventions using social media-based career information?

In addition to specific research questions, researchers need to consider methodological and ethical issues inherent in these types of studies. Methodological issues would need to address sampling concerns, instrumentation, and data collection in an online environment. Ethical issues would include protection of confidentiality and privacy (especially if participants are using social media platforms as part of the research), informed consent, instrumentation, online data storage, cultural considerations, and awareness of laws and statutes on data collection.

\section{Conclusion}

The use of social media has become increasingly common in the delivery of counseling services (Osborn, Kronholz, Finklea, \& Cantonis, 2014) and career services (Dyson, 2012; Osborn, \& LoFrisco, 2012). Social media has been perceived by practitioners to be a viable option for delivering information to individuals and clients (Kettunen et al., 2015b), and individuals are recognized as using social media for career development purposes beyond the boundaries of their career services relationships (e.g., NACE, 2013). Collaboratively creating information creates an environment of joint purpose around a topic, but is dependent upon individuals' ability to "evaluate, use, and contribute to these sources" (Kim et al., 2014). However, the potential contribution of social media-based career information will be 
compromised if individuals, clients, and practitioners fail to differentiate between valid and invalid information. Career practitioners have a key role in helping individuals and clients evaluate, use, and contribute to social media-based career information as they navigate and make career decisions. 


\section{References}

Ahlqvist, T., Bäck, A., Heinonen, S., \& Halonen, M. (2010). Road-mapping the societal transformation potential of social media. Foresight, 12(5), 3-26. doi:10.1108/14636681011075687

Alliance of Career Resource Professionals (2016a). Handbook of standards. Bloomington, IN: Author. Retrieved from http://www.acrpro.org/aws/ACRP/pt/sp/standards.

Alliance of Career Resource Professionals (2016b). Handbook of standards: Comparison tool. Bloomington, IN: Author. Retrieved from http://www.acrpro.org/aws/ACRP/pt/sp/standards.

Association of College and Research Libraries (2000). Information literacy competency standards for higher education. Chicago, IL: Author. Retrieved from www.ala.org/acrl/standards/informationliteracycompetency

Bimrose, J., \& Barnes, S.-A. (2011). Labour Market Information (LMI), Information Communications and Technologies (ICT) and Information, Advice and Guidance (IAG): The way forward? London: UK Commission for Employment and Skills. Retrieved from https://www2.warwick.ac.uk/fac/soc/ier/publications/2010/bimrose_lmi_and_ict_2010.pd $\underline{\mathrm{f}}$

Bimrose, J., Barnes, S.-A., \& Atwell, G. (2010). An investigation into the skills needed by connexions personal advisers to develop internet-based guidance. Reading, England: CfBT Education Trust.

Bimrose, J., Hughes, D., \& Barnes, S.-A. (2011). Integrating new technologies into careers practice: Extending the knowledge base. London, England: UK Commission for Employment and Skills. Retrieved from 
http://www.ukces.org.uk/assets/ukces/docs/publications/integrating-new-technololgiesinto-careers-practice.pdf

Bimrose, J., Kettunen, J., \& Goddard, T. (2015). ICT - the new frontier? Pushing the boundaries of careers practice. British Journal of Guidance \& Counselling, 43, 8-23. doi:10.1080/03069885.2014.975677

Brown, S. D. \& Ryan Krane, N. E. (2000). Four (or five) sessions and a cloud of dust: Old assumptions and new observations about career counseling. In S. D. Brown \& R. W. Lent (Eds.), Handbook of counseling psychology (3rd. ed) (pp. 740-766). New York: Wiley.

Dohn, N. B. (2009). Web 2.0: Inherent tensions and evident challenges for education. International Journal of Computer Supported Collaborative Learning, 4, 343-363. doi:10.1007/ s11412-009-9066-8

Dyson, E. (2012). Face-to-Facebook: A blended approach to careers work. Journal of the National Institute for Career Education and Counselling, 29, 27-32.

Hooley, T. (2012). How the internet changed career: Framing the relationship between career development and online technologies. Journal of the National Institute for Career Education and Counselling (NICEC), 29, 2-12.

Hooley, T., Hutchinson, J., \& Watts, A. G. (2010). Careering through the web. The potential of Web 2.0 and 3.0 technologies for career development and career support services. London: UK Commission for Employment and Skills. Retrieved from http://derby.openrepository.com/derby/bitstream/10545/198269/1/careering-through-theweb.pdf

Hooley, T., Shepherd, C., \& Dodd, V. (2015). Get yourself connected: Conceptualising the role of digital technologies in Norwegian career guidance. Derby: International Centre for 
Guidance Studies, University of Derby. Retrieved from http://derby.openrepository.com/derby/handle/10545/579570

Howieson, C., \& Semple, S. (2013). The impact of career websites: what's the evidence? British Journal of Guidance \& Counselling, 41, 287-301. doi:10.1080/03069885.2013.773960

Kaplan, A.M., \& Haenlein, M. (2010). Users of the world, unite! The challenges and opportunities of Social Media. Business Horizon, 53, 59-68.

doi:10.1016/j.bushor.2009.09.003

Kettunen, J., Sampson, J. P., \& Vuorinen, R. (2015a). Career practitioners' conceptions of competency for social media in career services. British Journal of Guidance \& Counseling, 43, 43-56. doi:10.1080/03069885.2014.939945 Retrieved from https://jyx.jyu.fi/dspace/handle/123456789/45919

Kettunen, J., Vuorinen, R., \& Sampson, J. P. (2015b). How do career practitioners experience social media in career services? The Career Development Quarterly, 63, 268-282. doi:10.1002/cdq.12018

Kim, K. S., Sin, S. J. \& Yoo-Lee, E. Y (2014) Undergraduates use of social media as information sources. College \& Research Libraries, 74, 442-457. doi:10.5860/crl.75.4.442

Kolbitsch, J. \& Maurer, H. (2006) The transformation of the web: How emerging communities shape the information we consume. Journal of Universal Computer Science, 12, 187213.

Makela, J. P. (2015). Ethical use of social networking technologies in career services. Broken Arrow, OK: Author. Retrieved from http://www.ncda.org/aws/NCDA/asset_manager/get_file/110167. 
Makela, J. P. \& Kettunen, J. (submitted). Ethical practice and social networking in career services. Reflections from the field. The Career Development Quarterly.

National Association of Colleges and Employers. (2013). The class of 2013 student survey report. Results from NACE's annual survey of college students. Bethlehem, PA: Author. Retrieved from www.naceweb.org

National Career Development Association (1991). Career software review guidelines. Broken Arrow, OK: Author. Retrieved from http://www.ncda.org/aws/NCDA/asset manager/get file/3402.

National Career Development Association (1992a). Guidelines for the preparation and evaluation of career and occupational information literature. Broken Arrow, OK: Author. Retrieved from http://www.ncda.org/aws/NCDA/asset manager/get file/3399.

National Career Development Association (1992b). Guidelines for the preparation and evaluation of video career media. Broken Arrow, OK: Author. Retrieved from http://www.ncda.org/aws/NCDA/asset manager/get file/3401.

National Career Development Association. (2011). National Survey of Working America. Retrieved from http:/www.ncda.org/aws/NCDA/asset_manager/get_file/37267?ver=8026

National Career Development Association. (2015). NCDA Code of Ethics. Retrieved from https://www.ncda.org/aws/NCDA/asset_manager/get_file/3395.

O'Reilly, T. (2007). What Is Web 2.0: Design patterns and business models for the next generation of software. International Journal of Digital Economics, 65, 17-37. 
Offer, M., \& Sampson, J. P. (1999). Quality in the content and use of information and communications technology in guidance. British Journal of Guidance and Counselling, 27, 501-516. doi:10.1080/03069889908256286

Osborn, D., Kronholz, J. F., Finklea, J. T., \& Cantonis, A. M. (2014). Technology-savvy career counselling. Canadian Psychology, 55(4), 258-265. doi:10.1037/a0038160

Osborn, D. S., \& LoFrisco, B. M. (2012). How do career centers use social networking sites? Career Development Quarterly, 60, 263-272. doi:10.1002/j.2161-0045.2012.00022.x

Sampson, J. P., Jr., \& Lumsden, J. A. (2000). Ethical issues in the design and use of Internetbased career assessment. Journal of Career Assessment, 8, 21-35. doi:10.1177/106907270000800103

Sampson, J. P., \& Makela, J. P. (2014). Ethical issues associated with information and communication technology in counseling and guidance. International Association for Educational and Vocational Guidance Journal, 14, 135-148. doi:10.1007/s10775-0139258-7.

Sampson, J. P., \& Osborn, D. S. (2014). Using information and communication technology in delivering career interventions. In P. J. Hartung, M. L. Savickas, \& W. B. Walsh (Ed.), APA handbook of career intervention, Volume 2: Applications (pp. 57-70). Washington, DC: American Psychological Association.

Sampson, J. P., Jr., Reardon, R. C., Peterson, G. W., \& Lenz, J. L. (2004). Career counseling and services: A cognitive information processing approach. Pacific Grove, CA: Wadsworth-Brooks/Cole.

Shen, Y. (2016). How credible are online product reviews? The effects of self-generated and system-generated cues on source credibility evaluation. Computers in Human Behavior, 55, 
$633-641$.

Watts, A. G. (2010). Policy issues relating to the use of ICT in lifelong guidance. Journal of the National Institute for Career Education and Counselling (NICEC), 25, 33-39.

Zalaquett, C. P., \& Osborn, D. S. (2007). Fostering counseling students' career information literacy through a comprehensive career web site. Counselor Education and Supervision, 46, 162-171. doi:10.1002/j.1556-6978.2007.tb00022.x 